\title{
Mild and Highly Efficient Method for Synthesis of 14-Aryl(alkyl)- $14 H$-dibenzo[a,j]xanthenes and 1,8-Dioxooctahydroxanthene Derivatives Using Pentafluorophenyl Ammonium Triflate as a Novel Organocatalyst
}

\author{
Samad KHAKSAR*, Nosratollah BEHZADI \\ Chemistry Department, Ayatollah Amoli Branch, Islamic Azad University, Amol, Iran
}

\begin{abstract}
A simple and facile synthesis of 14-aryl and alkyl-14H-dibenzo[a,j]xanthenes and 1,8-dioxooctahydroxanthene derivatives has been successfully developed by treatment of $\beta$-naphthol or dimedone with aldehydes under mild conditions in the presence of a pentafluorophenyl ammonium triflate (PFPAT) organocatalyst. These catalytic condensation reactions represent green chemical processes and the PFPAT organocatalyst is air-stable, cost-effective, easy to handle, and easily removed from the reaction mixtures.
\end{abstract}

Key words: pentafluorophenyl ammonium triflate; organocatalyst; xanthene; $\beta$-naphthol

CLC number: O643 Document code: A

Received 29 December 2011. Accepted 20 March 2012.

*Corresponding author.Fax: +98-121-2517071; E-mail: S.khaksar@iauamol.ac.ir; Samadkhaksar@yahoo.com

This work was supported by the Islamic Azad University, Ayatollah Amoli Branch.

English edition available online at Elsevier ScienceDirect (http://www.sciencedirect.com/science/journal/18722067).

14-Substituted-14H-dibenzo[a,j]xanthene derivatives have been found to possess a broad spectrum of biological activities, including antibacterial [1], anti-inflammatory [2], and antiviral activities [3]. Furthermore, these compounds have been used in photodynamic therapy [4] and as antagonists for paralyzing the action of zoxazolamine $[5,6]$. These compounds have also been used as dyes $[7,8]$, in laser technology [9], and in fluorescent materials for visualization of biomolecules [10] and as $\mathrm{pH}$ sensitive fluorescent materials for the visualization of biomolecules [11]. Classically, xanthene derivatives were synthesized either by the reaction of aryloxymagnesium halides with triethylorthoformate [12], the trapping of benzynes with phenols [13], or by the reaction of $\beta$-naphthol with 2-naphthol-1-methanol [14], formamide [15], carbon monoxide [16], and aldehydes or acetals [17-30]. Unfortunately, many of these existing methodologies suffer from one or more disadvantages such as prolonged reaction times, low yields, use of harmful organic solvents, requirement for an excess of catalyst/reagents, and harsh reaction conditions. Pentafluorophenyl ammonium triflate (PFPAT) has emerged as a highly efficient and effective potential Brønsted acid catalyst, imparting high levels of regio- and chemo-selectivity in a variety of chemical transformations, because of its low toxicity, air and water compatibility, operational simplicity, and remarkable ability to suppress side reactions in acid sensitive substrates $[31,32]$. In a continuation of our investigations on the de- velopment of novel synthetic methodologies [33-39], we herein report a new, convenient, mild, and efficient procedure for the synthesis of 14-aryl(alkyl)-14H-dibenzo[a,j] xanthenes and 1,8-dioxooctahydroxanthene derivatives catalyzed by PFPAT as an effective and novel organocatalyst requiring only mild reaction conditions (Scheme 1).

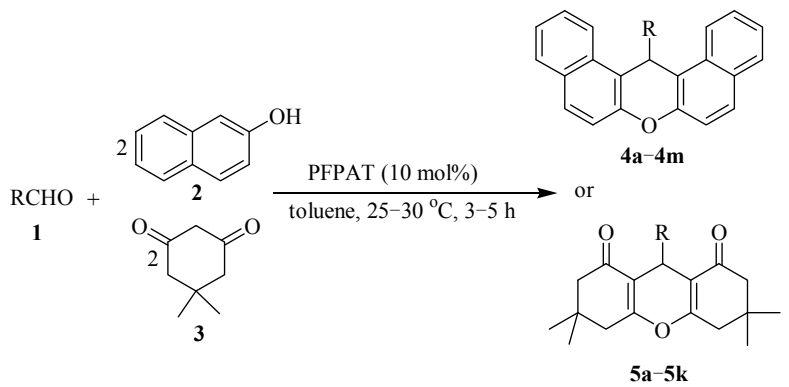

Scheme 1. Synthesis of xanthene derivatives.

\section{Experimental}

1.1 General procedure for the preparation of 14-aryl (alkyl)-14H-dibenzo[a,j]xanthenes

A toluene solution $(3 \mathrm{ml})$ of aldehyde $(1 \mathrm{mmol})$ and $\beta$-naphthol (2 mmol) was mixed with PFPAT (10 mol\%), and the resulting mixture was stirred for the appropriate reaction time. Upon completion of the reaction, as indicated by TLC, the organic phase was washed with $1 \mathrm{~mol} / \mathrm{L}$ aque- 
ous $\mathrm{NaOH}$ solution $(1 \mathrm{ml})$. The organic phase was then collected and the solvent removed in vacuo to give the crude product, which was purified by recrystallization from hot ethanol to afford pure product.

\subsection{General procedure for the preparation of 1,8-dioxooctahydroxanthenes}

A toluene solution $(3 \mathrm{ml})$ of aldehyde $(1 \mathrm{mmol})$ and 5,5-dimethyl-1,3-cyclohexanedione $(2 \mathrm{mmol})$ was mixed with PFPAT (10 mol\%), and the resulting mixture was stirred for the appropriate reaction time. Upon completion of the reaction, as indicated by TLC, the organic phase was washed with $1 \mathrm{~mol} / \mathrm{L}$ aqueous $\mathrm{NaOH}$ solution $(1 \mathrm{ml})$. The organic phase was then collected and the solvent removed in vacuo to give a crude product, which was purified by recrystallization from hot ethanol to afford pure product. Spectroscopic data for selected examples are listed as follows.

14-(4-Chlorophenyl)-14H-dibenzo[a,j]xanthene

(4a). Yellow solid; mp $291-292{ }^{\circ} \mathrm{C}$ (lit. $290-291{ }^{\circ} \mathrm{C}$ ). IR ( $\mathrm{KBr}$, $\left.\mathrm{cm}^{-1}\right): v 3066,2922,1622,1590,1514,1456,1397,1245$, $1237,1209,1140 .{ }^{1} \mathrm{H}$ NMR $\left(400 \mathrm{MHz}, \mathrm{DMSO}-\mathrm{d}_{6}\right): \delta 6.76$ (s, 1H), 7.18 (d, $J=6.8 \mathrm{~Hz}, 2 \mathrm{H}), 7.46-7.64(\mathrm{~m}, 10 \mathrm{H}), 8.92$ $(\mathrm{d}, J=7.79 \mathrm{~Hz}, 2 \mathrm{H}), 8.66(\mathrm{~d}, J=7.6 \mathrm{~Hz}, 2 \mathrm{H}) .{ }^{13} \mathrm{C}$ NMR $\left(100 \mathrm{MHz}\right.$, DMSO-d $\left.\mathrm{d}_{6}\right): \delta 36.3,117.4,118.1,123.4,123.7$, $125.0,127.4,128.8,129.1,129.6,130.1,131.1,131.2$, $144.8,148.4$.

9-Phenyl-3,3,6,6-tetramethyl-1,2,3,4,5,6,7,8-octahydroxa nthene-1,8-dione $(\mathbf{5 g})$. White solid; $\mathrm{mp} 204-205{ }^{\circ} \mathrm{C}$ (lit. 204-206 $\left.{ }^{\circ} \mathrm{C}\right)$. IR $\left(\mathrm{KBr}, \mathrm{cm}^{-1}\right): v 2954,1664,1364,1199 .{ }^{1} \mathrm{H}$ NMR (400 MHz, DMSO-d $\left.\mathrm{d}_{6}\right): \delta 0.90(\mathrm{~s}, 6 \mathrm{H}), 1.04(\mathrm{~s}, 6 \mathrm{H})$, 2.09 (d, $J=16.1 \mathrm{~Hz}, 2 \mathrm{H}), 2.27$ (d, $J=16.2 \mathrm{~Hz}, 2 \mathrm{H}), 2.53$ (d, $J=17.1 \mathrm{~Hz}, 2 \mathrm{H}), 2.58(\mathrm{~d}, J=17.7 \mathrm{~Hz}, 2 \mathrm{H}), 4.53(\mathrm{~s}, 1 \mathrm{H})$, $7.10(\mathrm{t}, J=7.0 \mathrm{~Hz}, 1 \mathrm{H}), 7.18(\mathrm{~d}, J=7.0 \mathrm{~Hz}, 2 \mathrm{H}), 7.21(\mathrm{t}, J$ $=7.20 \mathrm{~Hz}, 2 \mathrm{H}) \cdot{ }^{13} \mathrm{C}$ NMR $\left(100 \mathrm{MHz}\right.$, DMSO- $\left.\mathrm{d}_{6}\right): \delta 27.7$, 29.6, 32.3, 32.6, 41.3, 51.2, 116.1, 126.8, 128.4, 128.8, $144.5,162.7,196.8$.

\section{Results and discussion}

A series of comparative experiments were initially performed to assess the effectiveness of PFPAT versus other acidic catalysts in the formation of benzoxanthene. In some cases, data for other acidic catalysts were taken from the literature. The results are shown in Table 1. PFPAT was found to be the most efficient of all the catalysts tested, in terms of time, yield, and temperature (Table 1). A survey of possible solvents revealed toluene to be the best choice. It is worthy of note that the toluene was used directly without rigorous drying. Low yields were obtained when $\mathrm{CH}_{2} \mathrm{Cl}_{2}$ or water was employed as the solvent. Some dependence on
Table 1 The synthesis of 14-(4-nitrophenyl)-14H-dibenzo[a,j] xanthene using different catalysts

\begin{tabular}{lcccc}
\hline Catalyst & $\begin{array}{c}\text { Time } \\
(\mathrm{h})\end{array}$ & $\begin{array}{c}\text { Yield } \\
(\%)\end{array}$ & $\begin{array}{c}\text { Temperature } \\
\left({ }^{\circ} \mathrm{C}\right)\end{array}$ & Ref. \\
\hline Iodine & 2.5 & 85 & 90 & {$[24]$} \\
$p$-TsOH & 20 & 93 & reflux & {$[18]$} \\
Sulfamic acid & 2.5 & 90 & 125 & {$[26]$} \\
$\mathrm{H}_{2} \mathrm{SO}_{4} / \mathrm{SiO}_{2}$ & 1 & 97 & 125 & {$[27]$} \\
{$\left[\mathrm{TEBSA}_{[}\left[\mathrm{HSO}_{4}\right]\right.$} & $5 \mathrm{~min}$ & 93 & 120 & {$[28]$} \\
$\mathrm{H}_{14}\left[\mathrm{NaP}_{5} \mathrm{~W}_{30} \mathrm{O}_{110}\right]$ & 1 & 99 & 90 & {$[29]$} \\
$\mathrm{Sc}\left[\mathrm{N}\left(\mathrm{SO}_{2} \mathrm{C}_{8} \mathrm{~F}_{17}\right)_{2}\right]_{3}$ & 2 & 95 & 110 & {$[30]$} \\
PFPAT $\left(10 \mathrm{~mol}_{\%}\right)$ & 3 & 98 & r.t. & this work \\
PFPAT $(20 \mathrm{~mol} \%)$ & 3 & 98 & r.t. & this work \\
PFPAT $(5 \mathrm{~mol} \%)$ & 6 & 75 & r.t. & this work \\
\hline
\end{tabular}

the amount of PFPAT used was also observed. A satisfactory result was obtained in the presence of $10 \mathrm{~mol} \%$ PFPAT and no discernible improvement was noted when the catalyst loading was increased to $20 \mathrm{~mol} \%$. A decrease in the catalyst loading to $5 \mathrm{~mol} \%$, however, led to a reduction in product yield.

Using these optimized reaction conditions, the scope and efficiency of this approach was explored for the synthesis of a wide variety of substituted 14-aryl- and 14-alkyl-14Hdibenzo[a,j]xanthenes and the results are summarized in Table 2 . The reactions of variety of structurally diverse aldehydes with $\beta$-naphthol were investigated using the optimized reaction conditions (Scheme 1). It was found that all the reactions proceeded smoothly to give the corresponding benzoxanthenes $(\mathbf{4 a}-\mathbf{4 m})$ in high yields (Table 2). This protocol tolerates aromatic aldehydes containing both electron-donating and electron-withdrawing substituents well. The electronic effects and the nature of the substituents on the aldehydes showed some clear trends in terms of yields and reaction times. Aromatic aldehyde substrates with electron-withdrawing groups reacted well at faster reaction rates than aromatic aldehyde substrates with electron-donating groups. Ortho-substituted aromatic aldehydes, however, did not react as smoothly, likely because of steric hindrance, and longer reaction times were required to get the corresponding products in high yields (Table 2, entries 2 and 7). Longer reaction times were also required when aliphatic aldehydes were employed for the corresponding xanthenes to be obtained in good yields (Table 2, entries 12 and 13). We also examined the effect of solvents, revealing that the best yield was obtained in toluene, whereas much lower yields were observed with other solvents, including dichloromethane and acetonitrile.

To further demonstrate the applicability of this method, the preparation of 1,8-dioxooctahydroxanthene derivatives was also investigated. The reaction of 4-chlorobenzaldehyde with 5,5-dimethyl-1,3-cyclohexanedione in the presence of 
Table 2 Synthesis of 14-aryl- and 14-alkyl-14H-dibenzo $[a, j] x a n t h e n e s$ in the presence of PFPAT

\begin{tabular}{|c|c|c|c|c|}
\hline Entry & Aldehyde & Product & Time (h) & Yield of $4(\%)$ \\
\hline 1 & & $4 a$ & 3 & 97 \\
\hline 2 & & $4 b$ & 4 & 95 \\
\hline 3 & & $4 c$ & 3 & 96 \\
\hline 4 & & $4 d$ & 4 & 90 \\
\hline 5 & & $4 e$ & 3 & 92 \\
\hline 6 & & $4 f$ & 3 & 92 \\
\hline 7 & & $4 g$ & 4 & 90 \\
\hline 8 & & $4 h$ & 4.5 & 90 \\
\hline 9 & & $4 i$ & 5 & 85 \\
\hline 10 & & $4 j$ & 5 & 92 \\
\hline 11 & & $4 k$ & 4 & 90 \\
\hline 12 & $\mathrm{H}$ & 41 & 5 & 90 \\
\hline 13 & $\mathrm{CHO}$ & $4 \mathrm{~m}$ & 5 & 88 \\
\hline
\end{tabular}

PFPAT under similar conditions was initially investigated as a model reaction. As expected, these substrates underwent a smooth, one pot conversion to give the corresponding 1,8-dioxooctahydroxanthene derivatives in excellent yields (Table 3, entry 1). With the optimized conditions in hand, to explore the scope and generality of the reaction, we extended our study with other structurally varied aromatic, heteroaromatic, and aliphatic aldehydes to prepare a series of 9-aryl/heteroaryl/alkyl-3,3,6,6-tetramethyl-1,2,3,4,5,6,7, 8-octahydroxanthene-1,8-diones (Table 3, entries 1-11). A remarkable feature of this improved protocol was the tolerance of the current reaction conditions for a variety of functional groups, including ether, alkyl, nitro, and halide groups.

In addition, the PFPAT catalyst was easily removed from the reaction mixture after work-up, by washing with an aqueous $\mathrm{NaOH}$ solution to remove the $\mathrm{CF}_{3} \mathrm{SO}_{3} \mathrm{H}$, followed by distillation under reduced pressure $\left(\mathrm{C}_{6} \mathrm{~F}_{5} \mathrm{NH}_{2}\right.$ : bp $153{ }^{\circ} \mathrm{C}$ at $760 \mathrm{mmHg}$ ).
Table 3 Synthesis of tetramethyloctahydroxanthene-1,8-diones in the presence of PFPAT

\begin{tabular}{|c|c|c|c|c|}
\hline Entry & Aldehyde & Product & Time (h) & Yield of $5(\%)$ \\
\hline 1 & & $5 a$ & 3 & 97 \\
\hline 2 & & $5 b$ & 4 & 95 \\
\hline 3 & & $5 c$ & 3 & 96 \\
\hline 4 & & 5d & 4 & 90 \\
\hline 5 & & $5 e$ & 3 & 92 \\
\hline 6 & & $5 f$ & 3 & 92 \\
\hline 7 & & $5 \mathrm{~g}$ & 4.5 & 90 \\
\hline 8 & & $5 \mathrm{~h}$ & 4.5 & 90 \\
\hline 9 & & $5 \mathbf{i}$ & 5 & 85 \\
\hline 10 & & $5 \mathbf{j}$ & 4 & 92 \\
\hline 11 & 0 & $5 \mathbf{k}$ & 6 & 85 \\
\hline
\end{tabular}

\section{Conclusions}

A simple and highly efficient method for the synthesis of 14-substituted-14H-dibenzo[a,j]xanthenes has been developed via the condensation of $\beta$-naphthol with aldehydes catalyzed by pentafluorophenyl ammonium triflate in toluene at room temperature. The present approach offers the advantages of simple methodology, clean and mild reaction conditions, high atom-economy, short reaction time, low environmental impact, wide substrate scope, high yield, and excellent product purity.

\section{References}

1 Takeshiba H. JP 56005 480. 1981

2 Poupelin J P, Saint-Rut G, Foussard-Blanpin O, Narcisse G, Uchida-Ernouf G, Lacroix R. Eur J Med Chem, 1978, 13: 67

3 Lambert R W, Martin J A, Merrett J H, Parkes K E B, Thomas G J. Chem Abstr, 1997, 126: 212377y

4 Ion R M, Frackowiak D, Planner A, Wiktorowicz K. Acta Biochim Pol, 1998, 45: 833

5 Saint-Ruf G, De A, Hieu H T. Bull Chim Ther, 1972, 7: 83 
6 Saint-Ruf G, Hieu H T, Poupelin J P. Naturwissenschaften, 1975, 62: 584

7 Banerjee A, Mukherjee A K. Stain Technol, 1981, 56: 83

8 Menchen S M, Benson S C, Lam J Y L, Zhen W, Sun D, Rosenblum B B, Khan S H, Taing, M U S. US 6583168. 2003

9 Sirkecioglu O, Talinli N, Akar A. J Chem Res, Synop, 1995: 502

10 Bekaert A, Andrieux J, Plat M. Tetrahedron Lett, 1992, 33: 2805

11 Knight C G, Stephens T. Biochem J, 1989, 258: 683

12 Casiraghi G, Casnati G, Cornia M. Tetrahedron Lett, 1973, 14: 679

13 Knight D W, Little P B. J Chem Soc, Perkin Trans 1, 2001: 1771

14 Sen R N, Sarkar N N. J Am Chem Soc, 1925, 47: 1079

15 Papini P, Cimmarusti R. Gazz Chim Ital, 1947, 77: 142

16 Ota K, Kito T. Bull Chem Soc Jpn, 1976, 49: 1167

17 Rajitha B, Kumar B S, Reddy Y T, Reddy P N, Sreenivasulu N. Tetrahedron Lett, 2005, 46: 8691

18 Khosropour A R, Khodaei M M, Moghannian H. Synlett, 2005: 955

19 Kumar P S, Kumar B S, Rajitha B, Reddy P N, Sreenivasalu N, Reddy Y T. Arkivoc, 2006: 46

20 Pasha M A, Jayashankara V P. Bioorg Med Chem Lett, 2007, 17: 621

21 Shaterian H R, Ghashang M, Hassankhani A. Dyes Pigments, 2008, 76: 564

22 Su W K, Yang D, Can J, Zhang B. Tetrahedron Lett, 2008, 49: 3391
23 Saini A, Kumar S, Sandhu J S. Synlett, 2006: 1928

24 Mahdavinia G H, Rostamizadeh S, Amani A M, Emdadi Z. Ultrason Sonochem, 2009, 16: 7

25 Bhattacharya A K, Rana K C. Mendeleev Commun, 2007, 17: 247

26 Das B, Ravikanth B, Ramu R, Laxminarayana K, Vittal Rao B. J Mol Catal A, 2006, 255: 74

27 Dharma Rao G B, Kaushik M P, Halve A K. Tetrahedron Lett, 2012, 53: 2741

28 Hajipour A R, Ghayeb Y, Sheikhan N, Ruohoa A E. Synlett, 2010: 741

29 Heravi M M, Bakhtiari K, Daroogheha Z, Bamoharram F F. J Mol Catal A, 2007, 273: 99

30 Hong M, Cai C. J Fluorine Chem, 2009, 130: 989

31 Funatomi T, Wakasugi K, Misaki T, Tanabe Y. Green Chem, 2006, 8: 1022

32 Iida A, Osada J, Nagase R, Misaki T, Tanabe Y. Org Lett, 2007, 9: 1859

33 Khaksar S, Heydari A, Tajbakhsh M, Vahdat S M. Tetrahedron Lett, 2008, 49: 3527

34 Heydari A, Khaksar S, Tajbakhsh M. Synthesis, 2008: 3126

35 Khaksar S, Vahdat S M, Tajbakhsh M, Jahani F, Heydari A. Tetrahedron Lett, 2010, 51: 6388

36 Khaksar S, Heydari A, Tajbakhsh M, Vahdat S M. J Fluorin Chem, 2010, 131: 1377

37 Montazeri N, Khaksar S, Nazari A, Alavi S S, Vahdat S M, Tajbakhsh M. J Fluorine Chem, 2011, 132: 450

38 Khaksar S, Ostad S M. J Fluorine Chem, 2011, 132: 937

39 Khaksar S, Fattahi E, Fattahi E. Tetrahedron Lett, 2011, 52: 5943 